ISSN 1516-635X Oct - Dec 2015 / Special Issue Nutrition - Poultry feeding additives / 099-104 http://dx.doi.org/10.1590/1516-635xSpeciallssue Nutrition-PoultryFeedingAdditives099-104

Technical Note

\title{
Effects of the Dietary Inclusion of a Probiotic, a Prebiotic or their Combinations on the Growth Performance of Broiler Chickens
}

EAuthor(s)

\section{Murshed MA'}

Abudabos AM'

Department of Animal Production, College of Food and Agriculture Sciences, King Saud University, Riyadh, Saudi Arabia.

\section{-Mail Address}

Corresponding author e-mail address Prof. Alaeldein M. Abudabos

Animal Production, College of Food and Agriculture Sciences, King Saud University,

P. O. Box 2460, Riyadh 11451, Saudi Arabia

Tel: 00966597634578

Fax: 0096614678474

E-mail: alabudabos@gmail.com

\section{-Keywords}

Antimicrobial growth promoters (AGP) probiotic, prebiotic, symbiotic, broiler performance.

\section{ABSTRACT}

A total of 350-one-day old chicks were placed in 70 cages, with 14 cages per treatment. The following five treatment diets were fed for 14 days: $\mathrm{T} 1=$ non-supplemented, control diet $(\mathrm{CONT}) ; \mathrm{T} 2=\operatorname{diet}$ with antimicrobial growth promoter (AGP); $\mathrm{T3}=$ diet with a probiotic $(\mathrm{PROB}) ; \mathrm{T} 4=$ diet with a prebiotic $(\mathrm{PREB})$, and $\mathrm{T} 5=$ diet with the probiotic and the prebiotic (SYM). The growth experiment was carried out from 1 to 14 days of age. Feed and water were provided ad libitum and birds were maintained at 24-h light schedule. Diets were formulated to contain $3000 \mathrm{kcalME} / \mathrm{kg}$ and $21.5 \%$ crude protein, and the test materials were added on top. The cumulative results of 1 to 14 days of age revealed that broiler fed the AGP and PREB diets presented the highest BWG (305.5 and $297.3 \mathrm{~g}$, respectively), while those fed the CONT diet had the lowest BWG $(273.2 \mathrm{~g})(\mathrm{p}<0.05)$. On the other hand, the best FCR was obtained in broilers AGP and PROB (1.296 and 1.299 $\mathrm{g}: \mathrm{g}$, respectively), while chicks on the CONT and SYM diet had the worst FCR (1.423 and $1.372 \mathrm{~g}: \mathrm{g}$, respectively) $(\mathrm{p}<0.01)$. The results showed broilers fed the non-supplemented diet consistently presented poor performance. It was concluded that PROB or PREB can serve as alternatives to antibiotic in broiler starter feeds, with no performance impairment.

\section{INTRODUCTION}

Antimicrobial growth promoters (AGPs) have been used at subtherapeutic doses in poultry diets to prevent diseases and to promote growth performance. The positive effects of AGPs on performance are well documented (Visek, 1978). AGPs improve broiler growth performance and reduce the populations of potentially-pathogenic organisms such as Clostridium perfringens, Salmonella and E. coli (Hume et al., 2011). However, the risk of developing cross-resistance and multiple antibiotic resistance in human pathogenic bacteria, which could result in proliferation of antibiotics-insensitive bacteria, has led to the ban or severe limitations of the use of AGPs in many countries. The objective of this study was to test a variety of safer products which could be used alternatives to AGPs in broiler diets during the starter period.

Many feed additives are presently used in the animal industry, such as probiotics, prebiotics, and symbiotics. Probiotics are live organisms which have been studied for their antimicrobial and growth promoter abilities (Teo \& Tan, 2006; Hume, 2011). Probiotics have been reported to prevent gut colonization by pathogenic bacteria, such as Clostridium perfringens and Salmonella spp., by the mechanism of competitive exclusion (Teo \& Tan, 2006; Abudabos et al., 2013). Prebiotics are a possible alternatives to AGPs in poultry diets. Prebiotics typically refers to 
oligosaccharides that are not digested by the animal's enzymes, but can selectively stimulate the replication of selected intestinal bacterial species, which have potential beneficial effects on the host's health. Prebiotics present more advantages compared with probiotics: while probiotics supply microbes beneficial to the gut, prebiotics are thought to selectively stimulate the beneficial microbes that already live in the gut (Yang et al., 2009).

Another possible alternative to AGPs are symbiotics. Symbiotics are combinations of probiotics and prebiotics, as well as other growth-promoting substances. Symbiotics have shown to have positive effects on gut health, diet digestibility, and live performance of broilers (Patterson and Burkholder, 2003).

The objective of the current study was to examine the effects of prebiotics, probiotics, and symbiotics on the growth performance ofbroilers during the starter period ( 1 to 14 days of age) in comparison with a standard AGP.

\section{MATERIALS AND METHODS}

\section{Growth Experiment and treatments}

The prebiotic, probiotic, symbiotic and antibiotic products were obtained commercially. Neoxyval (Sogeval Laboratory, France) was used as the reference AGP; each g contains $200 \mathrm{mg}$ oxy-tetracycline and $200 \mathrm{mg}$ neomycin. GalliPro is a probiotic (microbial feed additive) supplied by Biochem (Zusatzstoffe Handels- und Produktionsgesellschaft $\mathrm{mbH}$ | Küstermeyerstraße 16 | 49393 Lohne, Germany). GalliPro $®$ is a probiotic based on a naturally-occurring, superior, high-activity strain of Bacillus subtilis (DSM 17299) at a minimum concentration of $1.6 \times 10^{9}$ viable spores/g. TechnoMos is a prebiotic product supplied by Biochem (Zusatzstoffe Handels- und Produktionsgesellschaft mbH | Küstermeyerstraße 16 | 49393 Lohne, Germany). It is derived from the cell wall of the baker's yeast Saccharomyces cerevisiae, rich in mannanoligosaccharides (MOS) and beta-1,3-glucans.

The experiment was conducted at the environmentally controlled battery room at King Saud University.

A total of 350 one-day-old Ross 308 broiler chicks were obtained from a commercial hatchery and were grouped by weight. Birds were then were allotted to 70 experimental cages with five chicks per cage in a fourdeck cage system, equipped with electrically heated battery brooders with raised wire floors. The dimension for each cage was $50 \mathrm{~cm}$ length, $60 \mathrm{~cm}$ width and $36 \mathrm{~cm}$ depth. The environmental temperature was kept at $22^{\circ} \mathrm{C}$ until the end of the experiment. At the hatchery, the chicks were vaccinated against Infectious Bronchitis, Marek's disease and Newcastle disease. Vitamins were supplemented in the drinking water for the first three days. The growth experiment was carried out from 1 to 14 days of age. Feed and water were provided ad libitum and birds were maintained at $24 \mathrm{~h}$ light schedule.

Chicks were given the experimental diets from 1 to 14 days of age. Corn-soybean meal based diets were formulated to contain $3000 \mathrm{kcalME} / \mathrm{kg}$ and $21.5 \%$ crude protein, respectively. The test materials were added on the top (Table 1).

Table 1 - Ingredient and analyzed nutrient content of the control starter diet

\begin{tabular}{|c|c|}
\hline Ingredients & $\%$ \\
\hline Yellow corn & 62.45 \\
\hline Soybean meal & 31.0 \\
\hline Palm oil & 2.19 \\
\hline Di-calcium phosphate & 2.50 \\
\hline Ground limestone & 0.73 \\
\hline Choline chloride & 0.05 \\
\hline DL-methionine & 0.26 \\
\hline L- lysine & 0.18 \\
\hline Salt & 0.25 \\
\hline Threonine & 0.07 \\
\hline V-M premix ${ }^{1}$ & 0.20 \\
\hline Total & 100 \\
\hline $\begin{array}{l}\text { Chemical Analysis } \\
\mathrm{ME}, \mathrm{kcal} / \mathrm{kg}\end{array}$ & 3000 \\
\hline Crude protein, \% & 21.5 \\
\hline Non phytate P, \% & 0.50 \\
\hline Calcium, \% & 1.00 \\
\hline Lysine, \% & 1.20 \\
\hline Methionine, \% & 0.55 \\
\hline SAA, $\%$ & 0.90 \\
\hline Threonine, \% & 0.85 \\
\hline \multicolumn{2}{|c|}{$\begin{array}{l}\text { 'Vitamin-mineral premix contains the following per kg: vitamin } \mathrm{A}, 2400000 \mathrm{IU} \text {; vitamin } \\
\text { D, } 1000000 \mathrm{IU} \text {; vitamin } \mathrm{E}, 16000 \mathrm{IU} \text {; vitamin } \mathrm{K}, 800 \mathrm{mg} \text {; vitamin B1, } 600 \mathrm{mg} \text {; vitamin } \\
\mathrm{B}_{2^{\prime}}, 600 \mathrm{mg} \text {; vitamin } \mathrm{B}_{6^{\prime}}, 1000 \mathrm{mg} \text {; vitamin } \mathrm{B}_{1^{\prime}} 6 \mathrm{mg} \text {; niacin, } 8000 \mathrm{mg} \text {; folic acid, } 400 \\
\text { mg; pantothenic acid, } 3000 \mathrm{mg} \text { biotin } 40 \mathrm{mg} \text {; antioxidant, } 3000 \mathrm{mg} \text {; cobalt, } 80 \mathrm{mg} \\
\text { copper, } 2000 \mathrm{mg} \text {; iodine, } 400 \text {; iron, } 1200 \mathrm{mg} \text {; manganese, } 18000 \mathrm{mg} \text {; selenium, } 60 \\
\text { mg, and zinc, } 14000 \mathrm{mg} \text {. }\end{array}$} \\
\hline
\end{tabular}

Chicks received one of the five dietary treatments as follows:

1) Control (CONT).

2) Control $+0.05 \mathrm{~g}$ antibiotic/kg (AGP).

3) Control $+0.2 \mathrm{~g}$ probiotic/kg (PROB).

4) Control +0.75 (starter) and 0.6 (finisher) $g$ prebiotic/kg (PREB).

5) Control $+(0.2 \mathrm{~g}$ probiotic/ $\mathrm{kg}+0.6 \mathrm{~g}$ prebiotic/ $\mathrm{kg})(\mathrm{SYM})$. 


\section{Measurements}

Feed intake and body weight were recorded weekly by pen, and feed conversion ratio (FCR) was calculated. Mortality was checked daily and weights of dead birds were used to adjust FCR.

\section{Statistical analysis}

Data were submitted to analysis of variance (ANOVA) for a complete randomized block design using the general linear models procedure of SAS software (SAS, 2003). When the ANOVA shows significant differences, Fisher's protected test was applied to compare the means. The overall level for statistical significance was set at $p<0.05$. All values were expressed as mean \pm standard error of the mean (SEM).

\section{RESULTS AND DISCUSSION}

Body weight gain (BWG), feed intake (FI) and feed conversion ratio corrected for mortality (FCR) are presented in Table 2.

During week 1, no significant differences in Fl were detected $(p>0.05)$. This could be explained by the small quantity of feed consumed during the first week.

However, BWG was affected by the treatments $(p<0.01)$. Broilers fed the CONT, AGP, and PREB diets gained more weight compared with those fed the SYM diet (94.6, 93.3, 89.3 and $87.3 \mathrm{~g}$ gain, respectively). Birds fed the PROB diet presented intermediate weight gain $(89.3 \mathrm{~g})$. On the other hand, those fed the CONT, AGP, PROB, and PREB diets converted feed more efficiently $(1.281,1.254,1.245$, and $1.287 \mathrm{~g}: \mathrm{g}$, respectively) compared with those receiving the SYM (1.417g:g) diet $(p<0.05)$.

During week 2, all broilers consumed similar amounts of feed ( $p>0.05)$, but their BWG and FCR were influenced by treatment (both at $p<0.01$ ). The broilers fed the supplemented diets (treatments 2 to 5 ) gained more weight than the CONT birds $(p<0.01)$. On the other hand, the birds on the supplemented diets (treatments 2 to 5) converted feed more efficiently compared with those fed the CONT diet $(p<0.01)$. Numerically, chicks which received AGP had the best FCR (1.315 g:g), but it was not statistically different from other supplemented groups $(1.315,1.324$, and $1.353 \mathrm{~g}: \mathrm{g}$, for PROB, PREB and SYM, respectively).

When data were analyzed for the entire experimental period (weeks 1 and 2), the results revealed that $\mathrm{FI}$ was not affected by any dietary treatments ( $p>0.05)$, while BWG and FCR were influenced by the dietary treatments $(p<0.05$ and $p<0.01$, respectively). Chicks fed the AGP and PREB diets presented had the highest BWG (305.5 and 297.3 g, respectively); however, the obtained values were not different from those obtained with the PROB and SYM diets (288.9 and $287.9 \mathrm{~g}$, respectively). The broilers that received the CONT diet had the lowest BWG during the two-week period (273.2 g).

The best FCR values during the cumulative period were obtained by the birds fed the AGP and PROB diets (1.296 and $1.299 \mathrm{~g}: \mathrm{g}$, respectively), which, however, were not statistically different from that presented by PREB birds (1.335 g:g). The birds in the CONT group (non-supplemented diet presented the worst FCR (1.423 g:g) followed by SYM (1.372 g:g).

Table 2 - Feed intake, body weight gain, and feed conversion ratio of broiler chickens during the trial

\begin{tabular}{|c|c|c|c|c|c|c|c|}
\hline & & & & & & SEM & $p$ \\
\hline & CONT & $A G P$ & PROB & PREB & SYM & & \\
\hline Week 1 & & & & & & & \\
\hline $\mathrm{FI}(\mathrm{g})$ & 120.5 & 117.0 & 111.0 & 118.7 & 123.5 & \pm 3.62 & NS \\
\hline BWG (g) & $94.6^{a}$ & $93.3^{a b}$ & $89.3^{b c}$ & $92.3^{a b}$ & $87.3^{c}$ & \pm 1.60 & 0.008 \\
\hline FCR(g:g) & $1.281^{b}$ & $1.254^{\mathrm{b}}$ & $1.245^{b}$ & $1.287^{b}$ & $1.417^{a}$ & \pm 0.039 & 0.015 \\
\hline Week 2 & & & & & & & \\
\hline $\mathrm{FI}(\mathrm{g})$ & 264.5 & 278.4 & 263.7 & 277.0 & 270.9 & \pm 5.67 & NS \\
\hline BWG (g) & $178.7^{b}$ & $212.2^{\mathrm{a}}$ & $200.0^{a}$ & $204.9^{a}$ & $200.7^{a}$ & \pm 5.67 & 0.005 \\
\hline FCR (g:g) & $1.511^{\mathrm{a}}$ & $1.315^{b}$ & $1.324^{b}$ & $1.358^{\mathrm{b}}$ & $1.353^{\mathrm{b}}$ & \pm 0.043 & 0.001 \\
\hline Cumulative & & & & & & & \\
\hline $\mathrm{FI}(\mathrm{g})$ & 385.1 & 395.4 & 374.8 & 395.7 & 394.4 & \pm 7.36 & NS \\
\hline BWG (g) & $273.2^{b}$ & $305.5^{a}$ & $288.9^{a b}$ & $297.3^{a}$ & $287.9^{a b}$ & \pm 6.62 & 0.019 \\
\hline FCR(g:g) & $1.423^{a}$ & $1.296^{c}$ & $1.299^{c}$ & $1.335^{b c}$ & $1.372^{\mathrm{ab}}$ & \pm 0.025 & 0.003 \\
\hline
\end{tabular}

\footnotetext{
abc means in the same row with different superscripts differ significantly.
} 
The results of the current study obtained with the evaluated probiotic agree with previous reports. Lund et al. (2005) conducted a series of feeding trials at different locations in EU and concluded that B. subtilis improved the body weight of broilers from $1 \%$ to $7 \%$. Similarly, Mountzouris et al. (2007) reported that the overall FCR of probiotic-fed broilers was not different from those fed an antibiotic. Both Rostagno et al. (2006) and Mokhtari et al. (2010)compared the efficacy of the same $B$. subtilis-based probiotic evaluated in the present experiment with the antibiotic avilamycin, and concluded that the broilers fed the probiotic presented similar performance than those fed the antibiotic.

Several mechanisms have been proposed to explain the positive effect of probiotics on growth performance. Probiotics have been reported to prevent gut colonization by pathogenic bacteria, such as C.perfringens, Escherichia coli, Campylobacter spp. and Salmonella spp. through the mechanism of competitive exclusion (Stern et al., 2001; Teo \& Tan, 2005; 2006; Cartman et al., 2008; Abudabos et al., 2013). Yurong et al. (2005), and Teo \& Tan (2006, 2007) showed that $B$. subtilis is capable of producing an antimicrobial factor against many bacteria, including C. perfringens, the causative agent of necrotic enteritis in broilers, by the immune modulation activity of the $B$. subtilis. Wilson et al. (2005) proposed that the growthsuppressing effect of pathogenic bacteria was due to the production of toxic metabolites that irritate the gut mucosa, thereby inhibiting nutrient absorption. In the current study, the probiotic group (PROB) presented similar performance as the antibiotic group, suggesting that the evaluated probiotic product may replace infeed antibiotics without any negative effect on broiler performance from 1 to 14 days of age.

The prebiotic product (PREB) used in the current study also improved broiler performance to a similar level as that obtained with the antibiotic (AGP). Hooge (2003) analyzed data from24 trials on the effects of a prebiotic (mannanoligosaccharide) on broiler performance and reported that FCR improved by $2.27 \%$ as a result of prebiotic supplementation.

Whereas probiotics are meant to bring beneficial microbes into the gut, prebiotics hypothetically act by selectively stimulating the beneficial microbes that are already present in the gut. Prebiotics serve as fuels for the endogenous microflora, thus providing the host with energy, metabolic substrates, and essential micronutrients (Gibson and Roberfroid, 1995; Yang et al., 2009). Prebiotic supplementation was shown to improve broiler growth and FCR (Podmaniczky et al., 2006; Zakeri and Mahdavi, 2006; Rozen, 2007). Several mechanisms are proposed to explain the positive effects of prebiotics on broiler performance and health. Such mechanisms include reducing disease incidence by inhibiting gut lining colonization by pathogenic bacteria, preventing them from proliferating and producing toxins (Valancony et al., 2001; Benites et al., 2008), reduction of intestinal pathogen counts (Benites et al., 2008), enhancement of the immune system (Ferket, 2002), and improvement of the morpho-functional characteristics of the gut (Ferket, 2002; Podmaniczky et al., 2006).

Symbiotics are a combination of probiotics and prebiotics (Collins and Gibson, 1999). Generally, prebiotics provide substrate for fermentation and this improves the survival of the probiotic organism. In the current study, the combination of the probiotic and the prebiotic products impaired broiler as compared to feeding the additives individually. Li et al. (2008) showed that combinations of prebiotics and probiotics (symbiotics) are often more effective when compared with the individual additives. Similarly, Awad et al. (2009) reported beneficial effects of a symbiotic over a probiotic on broiler performance. However, this was not the case in the current study.

\section{CONCLUSIONS}

The evaluated antibiotic growth promoter (neoxyval), probiotic (GalliPro), and prebiotic (TechnoMos) products improved broiler performance when compared with the control diet and with the symbiotic. Broilers fed the probiotic and the prebiotic products, individually, presented similar performance as those fed the antibiotic. The results of the present experiment show that both the evaluated probiotic and prebiotic products can serve as alternatives to the AGP in broiler feeds during the first two weeks of rearing without any adverse effects on their performance.

\section{ACKNOWLEDGEMENTS}

This project was supported by King Saud University, Deanship of Scientific Research, College of Food and Agriculture Sciences, Research Center.

\section{REFERENCES}

Abudabos A, Alyemni A, Al Marshad BA. Bacillus subtilis PB6 based-probiotic (CloSTAT ${ }^{\mathrm{TM}}$ ) improves intestinal morphological and microbiological status of broiler chickens under Clostridium Perfringens challenge. Int. J. Agric. Biology 2013;15(6):978-982.

Awad WA, Ghareeb K, Abdel-Raheem S, BöhmJ.Effects of dietary inclusion of probiotic and synbiotic on growth performance, organ weights, and intestinal histomorphology of broiler chickens. Poultry Science 2009;88:49-56. 
Bakst MR, Gupta K, Akuffo V. Comparative development of the turkey and chicken embryo from cleavage through hypoblast formation. Poultry Science 1997;76(1):83-90.

Benites V, Gilharry R, Gernat AG, Murillo JG. Effect of dietary Mannan Oligosaccharide from Bio-Mos or SAF-Mannan on live performance of broiler chickens. Journal of Applied Poultry Research 2008;17:471475.

Cartma ST, Ragione RML, Woodward MJ. Bacillus subtilis spores germinate in the chicken gastrointestinal tract. Applied Environmental Microbiology 2008;74(16):5254-5258

Ferket PR. Use of oligosaccharides and gut modifiers as replacements for dietary antibiotics. Proceedings of the 63th Minnesota Nutrition Conference; 2002 Sep 17-18; Eagan, Minnesota. USA; 2002

Gibson GR, Roberfroid MB. Dietary modulation of the human colonic microbiota: introducing the concept of prebiotics. Journal Nutrition 1995;125(6):1401-1412.

Hooge DM. Broiler chicken performance may improve with MOS. Feedstuffs 2003;6:11-13.

Hume ME. Historic perspective: prebiotics, probiotics, and other alternatives to antibiotics. Poultry Science 2011;90:2663-2669.

Li X, Qiang L, LiuCH. Effects of supplementation of fructooligosaccharide and/or Bacillus subtilis to diets on performance and on intestinal microflora in broilers. Archiv fur Tierzucht 2008;51(1):64-70.

Lund B, Hansen S, KürtiP. Efficacy of GalliPro - a microbial feed additive for broilers. Proceedings from the 15th European Synposium on poultry nutrition; 2005 Sept 25-29; Belatonfüred. Hungary; 2005. p.263-265.

Mokhtari R, Yazdani AR, Rezaei M., Ghorbani B. The effects of different growth promoters on performance and carcass characteristics of broiler chickens. Journal of Animal Veterinary Advances 2010;9(20):26332639.

Mountzouris KC, TsistsikosP, KalamaraE, NitshS, Schatzmayr G, Fegeros $K$. Evaluation of the efficacy of a probiotic containing Lactobacillus, Bifidobacterium, Enterococcus, and Pediococcus strains in promoting broiler performance and modualting cecal microflora composition and metabolic activities. Poultry Science 2007;86:309-317

Patterson JA, Burkholder KM. Application of prebiotics and probiotics in poultry production. Poult. Science 2003;82:627-631.
Podmaniczky B, Kocher A, Szabo ZS., Vegi B, Horel K, Korosi L, Molnar $A$. The effect of mannan oligosaccharides on growth performance of challenged broilers. World's Poultry Science Journal 2006;62:319-327.

Rozen GD. Holo-analysis of the efficacy of Bio-Mos in broiler nutrition. British Poultry Science 2007;48:21-26.

Rostagno MH, Wesley IV, Trampel DW, Hurd HS. Salmonella prevalence in market-age turkeys on-farm and at slaughter. Poultry Science 2006;85:1838-1842.

SAS Institute. SAS users guide: statistics. Version 9.1.3. Cary; 2002-2003.

Stern NJ, Cox NA, Bailey JS, Berrang ME, Musgrove MT.Comparison of mucosal competitive exclusion and competitive exclusion treatment to reduce Salmonella and Campylobacter spp. colonization in broiler chickens. Poultry Science 2001;80(2):156-160

Teo AYL, TanHM. Effect of Bacillus subtilis PB6 (CloSTAT) on broilers infected with a pathogenic strain of Escherichia coli. Journal of Applied Poultry Research 2006;15:229-235

Teo AYL, TanHM.Evaluation of the performance and Intestinal gut microflora of broilers fed on corn-soy diets supplemented with Bacillus subtilis PB6 (CloSTAT). Journal of Applied Poultry Research 2007;16:296-303.

Valancony $\mathrm{H}$, Humbert $\mathrm{F}$, Rukelibuga J, Bougon M, Balaine L, Lalande F. Comparison of some substitutes for antibiotic additives in diets for turkey poults. Effects on production and on resistance to salmonella colonization. Science Techology Avicoles 2001;35:25-34

Visek WJ. The Mode of Growth Promotion by Antibiotics. Journal of Anima Science 1978;46:1447-1469.

Yang Y, ljiPA, ChoctM. Dietary modulation of gut microflora in broiler chickens: a review of the role of six kinds of alternatives to in-feed antibiotics. World's Poultry Science Journal 2009;65:97-114.

Yurong Y, Ruiping S, Shimin Z, Yibao J. Effect of probiotics on intestinal mucosal immunity and ultrastructure of cecal tonsils ofchickens. Archives of Animal Nutrition 2005;59:237-246

Wilson J, Tice G, Brash ML, Hilaire S. Manifestations of Clostridium perfringens and related bacterial enteritides in broiler chickens. World's Poultry Science 2005;61:435-449.

Zakeri A, Mahdavi. The effect of Mos (mannan-oligosaccharide) on growth rate, productive parameters and amount of humoral immunity of broiler chickens. World's Poultry Science Journal 2006;(62):304p. 
